\title{
Cambio tecnológico en Córdoba: la categoría "regante" y la emergencia de una nueva identidad agraria
}

1941-2016 75 AÑOS

RMA

Antropología Social
Technological change in Córdoba: the "regante" category and the emergency of a new agrarian identity

Constanza Riera*

* CONICET, Programa de Investigación en Recursos Naturales y Ambiente, Instituto de Geografía, Facultad de Filosofía y Letras, Universidad de Buenos Aires.

E-mail: consriera@yahoo.com.ar

\begin{abstract}
Resumen
La adopción de riego mecanizado en Córdoba impulsó un proceso de génesis identitaria que resultó en la creación de la categoría "regante" para distinguir a un nuevo tipo de agricultor en el agro cordobés. En este trabajo me concentro en este efecto del cambio tecnológico que tuvo lugar en las planicies orientales de la provincia de Córdoba, Argentina, analizando el contenido semántico de dicha categoría. A partir de un estudio etnográfico argumento que ser "regante" implica ser un productor empresario e innovador, lo que a nivel del sentido común se traduce en ser un "productor de punta". Trabajé el espacio agrario bajo riego mecanizado de dicha provincia a partir de dos casos de estudio, uno Pampeano y otro en Traslasierra, a los cuales analicé comparativamente. Este esquema me permitió observar que hay rasgos comunes que son claves para comprender este proceso como parte de la agriculturización y la difusión del agronegocio, y diferencias fundamentales para valorar la participación de la tecnología en la construcción de esta nueva identidad agraria.
\end{abstract}

Palabras clave: tecnología; riego; agricultura familiar; empresario innovador; Córdoba (Argentina).

\begin{abstract}
The adoption of mechanized irrigation in Córdoba drove a process of identity genesis that turned out in the creation of the "irrigator" category to distinguish a new type of actor in rural Córdoba, Argentina. In this paper I focus on the effect of technological change that took place in the eastern plains of that province, analyzing the semantic content of the category. From an ethnographic perspective, I argument that being "irrigator" means being an entrepreneur and an innovative producer. These meanings are translated into being a "cutting-edge producer" by the common sense of local farmers. I worked comparatively the agricultural area under mechanized irrigation of Córdoba from two case studies, one Pampeano and another in Traslasierra. This scheme allowed me to observe that beyond the local particularities, there are key common traits to understand this process as part of the agriculturization and dissemination of agribusiness, and fundamental differences to assess the participation of technology in the construction of this new agrarian identity.
\end{abstract}

Key words: technology; irrigation; family farm; entrepreneur; Córdoba (Argentina).

Desde mediados de la década de 1990 el riego de cultivos extensivos, como trigo, maíz y soja, comenzó a expandirse por zonas agrícolas que eran tradicionalmente de secano. Gracias a un nuevo sistema de riego mecanizado, por aspersión y pivote central, abastecido con agua subterránea, fue creciendo el área irrigada en la provincia de Córdoba hasta alcanzar casi 90.000 ha en 2011 según las últimas estimaciones disponibles (Riera y Barrionuevo 2015). Esta adopción tecnológica significó "otra manera de hacer agricultura", como refieren sus usuarios, modificando física y socialmente el espacio agrario. En este trabajo me propongo analizar uno de los principales efectos de la adopción de esta tecnología: el surgimiento de una identidad productiva encarnada en el productor "regante".

Los procesos de cambio tecnológico en la agricultura ha sido un tema muy estudiado por las ciencias sociales por su relevancia para superar factores biológicos y climáticos que obstaculizan el desarrollo del capitalismo (Llambí 1988; Reca y Parellada 2001). Estos procesos son objeto de interés para la antropología porque implican importantes transformaciones socioculturales. La tecnología forma parte de un sistema social total en la que cualquier hecho que es tecnológico es también y al mismo tiempo político, social y simbólico; comporta 
un conjunto de relaciones sociales y por lo tanto, tiene significado (Vessuri 1980; Pfaffenberger 1992; Ingold 2000).

Más específicamente, la adopción de tecnología ha sido tomada como un indicador del desarrollo de las fuerzas productivas y vinculada a la cuestión de la diferenciación social y descomposición del campesinado ${ }^{1}$ (Archetti y Stölen 1975; Bartolomé 1975; De Janvry 1980; Piñeiro y Llovet 1986; Murmis 1991 [1980]); un tipo de análisis que incluso se ha realizado para el estudio de otros sistemas de riego (Pfaffenberger 1990).

Durante 1970 la explicación de este proceso estuvo dominada por la teoría marxista del desarrollo, pero a partir de 1980 la pérdida de confianza en la capacidad explicativa de esta teoría, vista cada vez más como teleológica y funcionalista, hizo que dichas explicaciones entraran en un impasse (Booth 1994). Se enfatizó entonces la necesidad de analizar empíricamente los procesos de expansión del capitalismo y describir el cambio tecnológico sin anticipar un sólo sentido general, de modo de rescatar el carácter plural del desarrollo.

Desde entonces, la existencia de procesos de diferenciación social entre los agricultores es un interrogante empírico a partir del cual se intenta dar cuenta de la creación de nuevas categorías sociales, como las de "pequeños terratenientes rentistas" (Barsky y Dávila 2008), "pequeños y medianos empresarios agrarios" (Gras 2009) o "empresarios agrarios familiares" (Pritchard et al. 2007).

Por ello, aquí procuro analizar la adopción de tecnología de riego en una de sus consecuencias principales desde el punto de vista sociocultural. Esta es la creación del "regante" como una categoría específica de actores. Sostengo que ésta categoría conlleva el significado de empresario innovador, lo que a nivel del sentido común se traduce como "productor de punta", efecto de una lógica de distinción que posiciona a los productores que tienen riego en la cúspide de la jerarquía social del espacio agrario cordobés.

A partir de este análisis, argumento que la inversión en la tecnología de riego responde a condiciones de estrés hídrico pero incluye factores que exceden lo estrictamente técnico ya que involucra la valoración de la innovación y la

\footnotetext{
1 Éste es un problema clásico dentro de la antropología y sociología rural y hace referencia a la persistencia del campesinado en el capitalismo ya que, desde una posición marxista, se sostenía que estaba destinado a desaparecer como consecuencia de la diferenciación social (De Janvry 1980). Por esta última se entendía los procesos de transformación que surgen como producto de la concentración capitalista en el agro que actuaba "descomponiendo" los estratos sociales campesinos en nuevos tipos sociales agrarios (Murmis 1991[1980]). Dicho proceso podía tener dos direcciones: "hacia abajo", resultando en la proletarización de los campesinos; o "hacia arriba", con la capitalización y transformación en pequeños capitalistas agrarios -o farmers- (Archetti y Stölen 1975; Bartolomé 1975).
}

eficiencia como rasgos culturales propios de una identidad productiva regante. Estas valoraciones son fundamentales para informar las prácticas que dinamizan el crecimiento de la agricultura bajo riego produciendo cambios sociales, además de los ecológicos.

La estrategia metodológica fue cualitativa y basada en el trabajo de campo etnográfico con el que reconstruí el espacio agrario bajo riego mecanizado en Córdoba. De cada una de las planicies de riego con agua subterránea de la provincia, divididas por las Sierras de Achala, seleccioné un caso de estudio con la intensión de obtener una representación del conjunto. Al Este se encuentra el área que forma parte de la Región Pampeana, en la eco-región Espinal, correspondiente a la jurisdicción de la Zona 1 del Consorcio de Usuarios de Agua Subterránea. De dicha zona tomé la cuenca del Río Segundo para el "caso Pampeano". Por otro lado, al Oeste está la Zona 2 del Consorcio de Usuarios de Agua Subterránea en Traslasierra, extremo Sur del Chaco Seco, de donde seleccioné la cuenca del Río Los Sauces para el "caso Traslasierra". ${ }^{2}$

Presento este último como caso comparativo en un apartado específico, mientras que mi análisis se centra en el caso Pampeano, donde este tipo de agricultura bajo riego comenzó su desarrollo. La comparación entre estos casos se fundamenta en que en ambos rige el mismo marco regulatorio para el uso del agua subterránea con una misma tecnología de riego, aunque se trate de sistemas agrícolas diferentes. Este ejercicio me permitió ver que, más allá de las particularidades locales, hay rasgos comunes que son claves para comprender este proceso de cambio tecnológico y sus consecuencias socioculturales.

El trabajo de campo consistió en seis viajes a terreno; tres durante 2008 (en los meses de junio, agosto y octubre), dos durante 2010 (en los meses de agosto y noviembre) y uno en 2012 (en el mes de marzo) en los que entrevisté a un total de 45 informantes, entre los que se encuentran todos los productores regantes de Río Segundo registrados en las instituciones correspondientes al momento del trabajo de campo (15 productores en el año 2008), algunos entrevistados más de una vez (ver Tabla 1). Esta muestra también incluye ingenieros agrónomos - de la Estación de Experimentación Agropecuaria (EEA) del Instituto Nacional de Tecnología Agropecuaria (INTA) en Manfredi, asesores Consorcio Regional de Experimentación Agrícola (CREA) y vendedores de insumos- (4 ingenieros) y productores de secano del mismo departamento (8 productores). Entre los agricultores entrevistados, varios eran productores CREA (8). En Traslasierra entrevisté a 7 productores agropecuarios y 4 técnicos e ingenieros agrónomos, en un universo que se caracteriza por la presencia de 11 grandes

\footnotetext{
${ }^{2}$ El caso Pampeano fue seleccionado en función de su cercanía con la capital provincial y el caso Traslasierra, debido a la concentración de la superficie regada en dicha zona.
} 
empresas agropecuarias, que se dividen entre el Valle de Conlara, San Luis, y Traslasierra, Córdoba; y 15 familias tradicionales productoras de papa (ver Tabla 1). También realicé charlas informales y entrevistas a miembros de la Comisión Directiva del Consorcio de Regantes de la Zona 1 -4 miembros, 2 secretarios- y de la Zona 2 -3 miembros-, y un técnico de la Subsecretaria de Recursos Hídricos de la provincia.

Realice observación y participación en situaciones como la Asamblea Ordinaria del Consorcio de Usuarios de Agua subterránea de la Zona 1, reuniones en el INTA, visité varias explotaciones agropecuarias y acompañé al personal del Consorcio y de la Subsecretaria de Recursos Hídricos en la realización de tareas de rutina.

\section{La agricultura de commodities bajo riego en Córdoba}

En la agricultura pampeana, la adopción de tecnología de riego por aspersión se produjo a partir de mediados de la década de 1990 como una medida complementaria a las transformaciones que ya se estaban sucediendo; es decir, se trató de una innovación que intensificaba el modelo de producción instalado con la adopción del paquete tecnológico compuesto por la siembra directa, semillas transgénica y glifosato. Por lo tanto acompañó el proceso de agriculturización que se dio en todo el país, consistente en cambios en el uso del suelo con el crecimiento de la superficie dedicada a la agricultura en detrimento de la ganadería (Barsky y Gelman 2000).

A partir de los datos censales disponibles (Censo Nacional Agropecuario-CNA-, INDEC, 1988 y 2002) se observa que en la provincia de Córdoba la superficie total cultivada se mantuvo más o menos estable durante la década de 1990, aunque con un fuerte crecimiento del trigo $(+150 \%)$ y la soja (+150\%), acompañado por el cultivo de maíz (+30\%), producto de la difusión del doble cultivo y un esquema de rotaciones especializada en commodities agrícolas. Este crecimiento de los cultivos anuales (+56\%) se dio en detrimento de la ganadería y los cultivos asociados a ella como los forrajeros. Al mismo tiempo, se registra la desaparición de una tercera parte de las Explotaciones Agropecuarias (EAP's) y el aumento de la cantidad de EAP's por encima de la 1000 ha lo que evidencia el proceso de concentración de la tierra y el aumento de la escala productiva que se dio paralelamente en la estructura agraria.

El CNA 2002 (INDEC) también registra los dos sistemas de riego existentes en la provincia. Por un lado, el riego gravitacional que es utilizado para la producción de hortalizas y cultivos regionales en pequeñas explotaciones, y por el otro, el riego por aspersión que se adopta para la producción de commodities propio de las EAP's medianas y grandes. Pero a partir del 2002, no hay fuentes censales disponibles y la información sobre la expansión de este último sistema depende de otro tipo de datos.

En diciembre de 2004 un estudio del INTA basado en imágenes satelitales determinó que en dicha provincia existían 76.820 ha bajo riego, de las cuales 58.000 ha se localizaban sobre los mejores suelos, en los que la escasez de lluvias era la principal limitante (Martellotto et al. 2005). El estudio concluye que a pesar de contar con gran potencialidad de crecimiento, el riego complementario era aún incipiente, y estimaba que en Córdoba se podrían regar aproximadamente 1.500.000 ha, dada la disponibilidad de recursos hídricos y la aptitud de los suelos.

Según un estudio publicado (Riera y Barrionuevo 2015), en el año 2011 ya había 1172 círculos de riego, lo que equivale a una superficie regada de 89.848 ha. Estos fueron concentrándose progresivamente hacia el corredor centro de Córdoba, y a partir de 2005 se registra además una cantidad significativa en Traslasierra. La mayor cantidad de riego se da entonces en el semiárido pampeano de la provincia, coincidiendo con la isohieta de $800 \mathrm{ml}$ que marca el límite a la agricultura de secano (Barros 2008). Por otro lado, el desarrollo del riego por aspersión en Traslasierra se dio en la mayoría de los casos sobre nuevas tierras para la agricultura, lo que implicó la eliminación del monte nativo (Montenegro 2012).

A partir de estos cambios territoriales se observa que la difusión del riego por aspersión es un fenómeno asociado al proceso de agriculturización (Riera y Barrionuevo 2015). En el área pampeana, como un factor consecuente que vino de la mano de la especialización agrícola reforzando la producción de commodities pre-existente y el doble cultivo. Mientras que en Traslasierra, la expansión del riego fue un factor promotor de este proceso ya que permitió extender la frontera agraria, agudizando algunos de sus principales efectos como la pérdida del bosque nativo, la concentración de la producción y la pampeanización de las agriculturas regionales (Morello et al. 2005).

\section{El caso Pampeano}

Algunas características socio productivas relevadas durante el trabajo de campo ayudan a contextualizar el estudio de caso Pampeano. En primer lugar, cabe mencionar que según el análisis censal realizado en otro lugar (Riera 2015), en Río Segundo la agricultura familiar es predominante, lo que se expresa en el perfil demográfico de la población rural como de las relaciones laborales más difundidas. Dentro de este contexto, los regantes son productores representativos del departamento.

En este trabajo utilizo la definición de Tort y Román (2005) que entienden la agricultura familiar como una forma de organización de la producción orientada a la obtención de 


\begin{tabular}{|c|c|c|c|c|c|c|c|}
\hline & $\begin{array}{l}\text { Eaps } \\
*\end{array}$ & $\begin{array}{l}\text { Extensión } \\
\text { total (has.) }\end{array}$ & $\begin{array}{l}\text { Superficie } \\
\text { regada } \\
\text { (has.) }^{\star \star}\end{array}$ & Tenencia & Sistema de riego & $\begin{array}{l}\text { Orientación } \\
\text { productiva }\end{array}$ & $\begin{array}{l}\text { Participación del } \\
\text { productor en } \\
\text { asociaciones } \\
\text { técnicas }\end{array}$ \\
\hline \multirow{13}{*}{$\begin{array}{l}\text { Caso } \\
\text { Pampeano }\end{array}$} & 1 & 150 & 72 & Propiedad & $\begin{array}{l}\text { Aspersión con } \\
\text { pivote central }\end{array}$ & $\begin{array}{l}\text { agricultura de } \\
\text { commodities }\end{array}$ & Ex Cambio Rural \\
\hline & 2 & 260 & 110 & $\begin{array}{l}\text { Propiedad y } \\
\text { arrendamiento }\end{array}$ & $\begin{array}{l}\text { Aspersión con } \\
\text { pivote central }\end{array}$ & $\begin{array}{l}\text { agricultura de } \\
\text { commodities }\end{array}$ & $\begin{array}{l}\text { Comisión asesora } \\
\text { INTA }\end{array}$ \\
\hline & 3 & 600 & 150 & $\begin{array}{l}\text { Propiedad y } \\
\text { arrendamiento }\end{array}$ & $\begin{array}{l}\text { Aspersión con } \\
\text { avance frontal }\end{array}$ & $\begin{array}{l}\text { agricultura de } \\
\text { commodities }\end{array}$ & no \\
\hline & 4 & 360 & 290 & Propiedad & $\begin{array}{l}\text { Aspersión con } \\
\text { pivote central }\end{array}$ & $\begin{array}{l}\text { agricultura de } \\
\text { commodities }\end{array}$ & CREA \\
\hline & 5 & 410 & 210 & Propiedad & $\begin{array}{l}\text { Aspersión con } \\
\text { pivote central } 1\end{array}$ & $\begin{array}{l}\text { agricultura de } \\
\text { commodities }\end{array}$ & $\begin{array}{l}\text { CREA } \\
\text { Ex-comisión } \\
\text { asesora INTA }\end{array}$ \\
\hline & 6 & 424 & 180 & $\begin{array}{l}\text { Propiedad y } \\
\text { arrendamiento }\end{array}$ & $\begin{array}{l}\text { Aspersión con } \\
\text { pivote central }\end{array}$ & $\begin{array}{l}\text { agricultura de } \\
\text { commodities }\end{array}$ & CREA \\
\hline & 7 & 450 & 300 & Propiedad & $\begin{array}{l}\text { Aspersión con } \\
\text { pivote central }\end{array}$ & $\begin{array}{l}\text { agricultura de } \\
\text { commodities }\end{array}$ & CREA \\
\hline & 8 & 500 & 273 & Propiedad & $\begin{array}{l}\text { Aspersión con } \\
\text { pivote central }\end{array}$ & $\begin{array}{l}\text { agricultura de } \\
\text { commodities }\end{array}$ & no \\
\hline & 9 & 564 & 400 & Arrendamiento & $\begin{array}{l}\text { Aspersión con } \\
\text { pivote central }\end{array}$ & $\begin{array}{l}\text { agricultura de } \\
\text { commodities }\end{array}$ & Ex CREA \\
\hline & 10 & 600 & 180 & Propiedad & $\begin{array}{l}\text { Aspersión con } \\
\text { pivote central }\end{array}$ & $\begin{array}{l}\text { agricultura de } \\
\text { commodities }\end{array}$ & Ex Cambio Rural \\
\hline & 11 & 600 & 374 & $\begin{array}{l}\text { Propiedad y } \\
\text { arrendamiento }\end{array}$ & $\begin{array}{l}\text { Aspersión con } \\
\text { pivote central }\end{array}$ & $\begin{array}{l}\text { agricultura de } \\
\text { commodities }\end{array}$ & Ex Cambio Rural \\
\hline & 12 & 800 & 420 & Propiedad & $\begin{array}{l}\text { Aspersión con } \\
\text { pivote central }\end{array}$ & $\begin{array}{l}\text { Tambo y } \\
\text { agricultura de } \\
\text { commodities }\end{array}$ & CREA \\
\hline & 13 & 1500 & 260 & Propiedad & $\begin{array}{l}\text { Aspersión con } \\
\text { pivote central }\end{array}$ & $\begin{array}{l}\text { agricultura de } \\
\text { commodities }\end{array}$ & no \\
\hline \multirow{7}{*}{$\begin{array}{l}\text { Caso } \\
\text { Traslasierra }\end{array}$} & 1 & 1380 & 750 & Propiedad & $\begin{array}{l}\text { Aspersión con } \\
\text { pivot central y } \\
\text { agua subterránea/ } \\
\text { Gravitacional con } \\
\text { agua superficial }\end{array}$ & $\begin{array}{l}\text { Papa y } \\
\text { cereales }\end{array}$ & $\begin{array}{l}\text { Traslasierra } \\
\text { Llanura Norte }\end{array}$ \\
\hline & 2 & 4400 & 4400 & $\begin{array}{l}\text { Propiedad y } \\
\text { arrendamiento }\end{array}$ & $\begin{array}{l}\text { Aspersión con } \\
\text { pivot central y } \\
\text { agua subterránea }\end{array}$ & $\begin{array}{l}\text { Papa y } \\
\text { cereales }\end{array}$ & $\begin{array}{l}\text { Traslasierra } \\
\text { Llanura Norte }\end{array}$ \\
\hline & 3 & 450 & 300 & $\begin{array}{l}\text { Propiedad y } \\
\text { arrendamiento }\end{array}$ & $\begin{array}{l}\text { Gravitacional con } \\
\text { agua superficial }\end{array}$ & Papa & no \\
\hline & 4 & 700 & 200 & $\begin{array}{l}\text { Propiedad y } \\
\text { arrendamiento }\end{array}$ & $\begin{array}{l}\text { Aspersión con } \\
\text { pivot central y } \\
\text { agua subterránea/ } \\
\text { Gravitacional con } \\
\text { agua subterránea }\end{array}$ & Papa & no \\
\hline & 5 & 800 & 500 & Propiedad & $\begin{array}{l}\text { Gravitacional con } \\
\text { agua superficial y } \\
\text { subterránea }\end{array}$ & $\begin{array}{l}\text { Papa y otras } \\
\text { hortalizas }\end{array}$ & no \\
\hline & 6 & 1700 & 800 & $\begin{array}{l}\text { Propiedad y } \\
\text { arrendamiento }\end{array}$ & $\begin{array}{l}\text { Gravitacional con } \\
\text { agua subterránea }\end{array}$ & Papa & no \\
\hline & $7^{\star \star \star}$ & 1600 & 150 & Propiedad & $\begin{array}{l}\text { Aspersión con } \\
\text { pivot central y } \\
\text { agua subterránea }\end{array}$ & Papa & no \\
\hline
\end{tabular}

Tabla 1. Explotaciones agropecuarias (EAPs) con riego relevadas durante el trabajo de campo en los dos casos de estudio

Table 1. Agricultural holdings (EAPS) with irrigation surveyed during fieldwork in the two case studies

Observaciones:

* Esta Tabla se confeccionó teniendo en cuenta las EAPs de los productores regantes entrevistados, aunque en muchos casos se entrevistaron a más de un productor por unidad productiva. La tabla no incluye las EAPs de los productores de secano entrevistados.

**En Traslasierra las ha regadas son las que efectivamente se encuentran en producción.

*** En esta EAP el productor propietario da en alquiler toda la superficie de su campo, con excepción de 150 ha en las que produce papa; cultivo que entra en la rotación de su arrendatario que produce papa y cereales.

Fuente: elaboración propia en base a entrevistas 
ganancia en el mercado con la participación directa del productor en el proceso productivo, muchas veces con el apoyo del trabajo familiar, aunque también de mano obra asalariada. La agricultura familiar tiene cierta capacidad de acumulación, lo que permite su reproducción ampliada a partir de la reinversión con el objeto de aumentar la productividad. Por otro lado, la herencia es la principal vía de acceso al manejo de la explotación, que es considerada más que un factor de producción, un patrimonio común que se trasmite por generaciones.

Más allá de las discusiones teóricas que la categoría agricultura familiar promueve dentro de los estudios sociales agrarios, rescato esta definición por ser lo suficientemente amplia como para incluir una diversidad de estrategias productivas en cuanto a las formas de organización que despliegan la empresas agropecuarias familiares, apropiadas para los agricultores familiares de la región pampeana. Según las caracteriza Melina Neiman (2010:8) estas "tienen una organización de tipo empresarial-familiar y cuya producción está destinada a la exportación de commodities", para la cual el análisis tradicional de los factores de producción (tierra, capital y trabajo) parece insuficiente para entender qué es lo distintivo de este tipo de unidades.

En el caso de los regantes de Río Segundo, como analizo más adelante, se observa que la presencia de relaciones de parentesco, tanto en la organización del trabajo, como en la forma de acceso a la propiedad, o en las motivaciones económicas que tienen los productores a la hora de desarrollar sus estrategias productivas dan cuenta de la importancia de lo familiar en la estructuración de su actividad.

Entre los rasgos descriptivos más generales, puede mencionarse que los regantes se dedican principalmente a la agricultura de commodities (trigo, maíz y soja), como lo hacen la mayoría de las EAP's del departamento, en campos que abarcan un rango de extensión de 150 ha a 1500 ha. Sin embargo, la extensión promedio es de 530 ha y la mayoría se concentra en el intervalo que va de 200 a 500 ha (ver Tabla 1). En este sentido, se ubican entre los estratos medios, donde también se concentra la mayor cantidad de EAP's de Río Segundo. Con respecto a la tenencia de la tierra, más de la mitad de los regantes trabajan sólo campos propios y el resto combinan propiedad con arrendamiento, principalmente a familiares que no se dedican a la producción.

Además del trabajo que aportan familiares del productor - especialmente en tareas de gestión- los regantes tienen al menos un empleado en forma permanente que reside en la explotación para que cuide el equipo de riego, ponerlo en funcionamiento y controlarlo. Sin embargo, la cantidad de empleados varía de uno a tres, siendo varios los productores que tienen dos.
La forma de asociación más difundida es la agrupación de productores con fines técnicos y productivos. Dentro de este tipo se desatacan los grupos CREA, y también los grupos organizados desde el INTA bajo el Programa Cambio Rural. La mayoría de ellos reciben asesoramiento técnico a través de dichas agrupaciones, y quienes no participan, lo obtienen de manera privada. Por otro lado, la asociación gremial es débil, pero varios de los regantes son miembros activos del Consorcio de Usuarios de Agua Subterránea de la Zona 1. En síntesis, por sus características sociales y culturales los regantes del caso Pampeano son pequeños empresarios agrícolas familiares, atributos que se ven reflejados en el contenido semántico de la categoría regante como analizo a continuación.

\section{Sobre los regantes como categoría social}

El riego como tecnología, mecánica en este caso, crea una nueva manera de realizar la actividad agrícola, además de nuevos significados sobre la misma y sobre quienes la realizan. Esta propiedad creadora de la tecnología constituye un acuerdo básico entre los antropólogos que se han dedicado a esta cuestión (Pfaffenberger 1988; Ingold 2001; Vessuri 1980), y también es percibida por los productores cuando afirman que el riego "es un factor transformador de la estructura social agraria", y que va a cambiar la "mentalidad del productor". En este sentido, el surgimiento de la categoría "regante" emerge como un tipo particular de agricultor dotado de una "manera de ser" que lo diferencia de otros. Por ello, "regante" es en primer lugar una categoría nativa, pero también puede ser una categoría teórica al construirse como tipo ideal a través de la conceptualización.

Siguiendo a Bourdieu (1990), parto del reconocimiento que la administración de los nombres es un componente esencial de la identidad social en el proceso de diferenciación. Las categorías que clasifican el universo social explicitan la lucha entre los agentes por el sentido del mundo y su posición en él. Así, la autodenominación como "productor regante" y el reconocimiento como tal, favorece la creación de una nueva identidad social. Ésta remite a la concepción de los grupos como "categorías de adscripción e identificación que son utilizadas por los actores mismos y tienen por lo tanto, la característica de organizar la interacción entre los individuos" (Barth 1976:10-11). Así, la noción de identidad supone la operación simultánea de un principio de semejanza (ser lo mismo que uno) y de diferencia (distinto de los diferentes) (Gundermann Kroll 1998:13), por lo que la emergencia de esta categoría de actores pone de manifiesto el esfuerzo por parte de un grupo de productores de diferenciarse del resto del universo social. Coincidentemente, el "nosotros" de los regantes se opone a la representación del productor "tradicional" que, en el caso pampeano, es el productor de secano y, en el caso de Traslasierra, como se verá más adelante, el regante por inundación. 
El ser regante comporta una serie de sentidos entre los que se encuentra el de ser un productor "de punta", un empresario innovador, eficiente en su actividad y preocupado por "hacer las cosas bien", rasgos que por un lado comparte con otros productores empresarios -de la región pampeana (Gras 2009) y de Traslasierra-, aunque la particularidad identitaria en este caso está dada por el uso del riego por aspersión. Esto es así, porque la posibilidad de disponer de agua en el momento justo redefine la actividad. Es decir, "son otros rindes", y en definitiva "es otra realidad" la que se vive productivamente, lo que hace que los productores cordobeses caractericen al riego como "revolucionario" a ambos lados de las sierras.

\section{Ser Empresario}

\section{Dos modelos agrícolas: agricultura familiar y agricultura} empresarial

La agricultura empresarial ha sido vista como la antítesis de la agricultura familiar (Archetti y Stölen 1975; Gras y Hernández 2009; Peón 1992), pero para los productores familiares regantes, la agricultura empresarial es más bien un modelo aspiracional. Estos son modelos nativos de representación del mundo que se centran sobre la propia posición dentro de la sociedad, y puesto que son modelos para la acción, forman parte del conocimiento de su sociedad y al mismo tiempo representan sus aspiraciones (Pitt-Rivers 1973). En este sentido existe una tensión entre ambos modelos que se expresa a nivel de las representaciones de productores y que se explica por la posición social de los regantes.

Para los regantes, el productor "tradicional" es el descendiente de la Pampa Gringa; su representante de tercera o cuarta generación. Son los "chacareros", es decir, productores familiares integrados a la economía capitalista, pero que "no la ven", esto es, incapaces de aprovechar las oportunidades de realizar negocios que impliquen mayores ganancias, porque tienen "aversión al riesgo" y no saben manejar los recursos del sistema financiero, un conocimiento imprescindible para formar parte del nuevo paradigma agrícola del agribusiness (Gras y Hernández 2009). Este productor es representado como una supervivencia del pasado, un actor social atrasado alter ego del ideal contemporáneo de la agricultura pampeana y donde la actividad agrícola que él desarrolla se presenta más como un modo de vida, que como una actividad orientada a la búsqueda activa de lucro, es decir, con cierta independencia de su resultado económico, en el límite de la racionalidad capitalista. El "chacarero" justamente se caracteriza por hacer las cosas como las hizo siempre, lo que lo dota de una actitud conservadora frente a los cambios, producto de una estructura patriarcal que inhibe a los más jóvenes de la familia de experimentar con nuevas tecnologías para la producción.

En oposición a esta representación se encuentra la figura del productor "empresario", que es "vivo", astuto y "picante para los negocios". Tiene la capacidad económica porque dispone de capital, lo que le permite asumir el riesgo económico necesario para aprovechar las oportunidades que le presenta el mercado. Dentro de este ideal, el empresario maneja grandes extensiones, pero fundamentalmente produce de manera "eficiente", es decir, es maximizador. Es innovador, experimenta, es "inquieto", y tiene iniciativas para realizar emprendimientos orientados a "subir en la cadena de agregado de valor". Además, es participativo, se vincula con las instituciones de transferencia técnica como el INTA o CREA, porque entiende que el asesoramiento profesional es un requisito indispensable para estar al tanto de las últimas tecnologías.

Sin embargo, en el caso del regante, la constitución de su identidad muestra una profunda cercanía con la agricultura familiar porque proviene de su mismo seno, lo que se expresa en tensiones que atraviesan su habitus (Bourdieu 1998). Estas tensiones son las que al mismo tiempo les confiere una particularidad distintiva. Dentro del conjunto heterogéneo que componen los productores regantes de Río Segundo, muchos tienen una trayectoria familiar dentro de la actividad y otros, si bien no cuentan con esta tradición, comparten rasgos centrales con quienes sí lo hacen, como por ejemplo, la preferencia por la inclusión de las relaciones de parentesco en el trabajo productivo, lo que se expresa en que padres e hijos trabajen juntos brindando un marco familiar a la actividad.

La diversidad que existe dentro de este universo de productores regantes, hace que, por ejemplo, sea posible encontrar, por un lado, a una familia (A) con una trayectoria de estilo "tradicional" aggiornada por los cambios experimentados por el sector. Se trata de una familia "gringa", de chacareros convertidos en empresarios agrarios. $Y$ por el otro, una familia (B) de empresarios de origen porteño cuyos encargados son jóvenes urbanos que, sin profesión ni oficio definido previo, se convirtieron en empresarios agrarios a partir de una trayectoria no chacarera.

En estas trayectorias aparecen dos estilos de empresario agrícola con similar escala productiva. Por un lado, (A) está más ligada a la forma tradicional de gestión de la producción, donde como descendientes de chacareros ítalo-argentinos acceden a la propiedad del campo por líneas de herencia que se remontan a las colonias agrícolas, cuyo conocimiento práctico es principalmente transmitido de generación en generación, y no hay una preocupación por el cálculo, la eficiencia y la planificación, ni una valoración del asesoramiento técnico profesional personalizado. Por el otro, (B) se trata de empresarios más vinculados a la gestión profesional, con una alta valoración del asesoramiento técnico privado y de las instancias de participación colectiva, donde la forma de acceso a la propiedad fue a través de una inversión inmobiliaria más entre otras inversiones de ese tipo; descendientes de empresarios urbanos, donde el conocimiento es 
transmitido por profesionales capacitados y otros productores experimentados bajo el método discusión grupal de los CREA, ${ }^{3}$ de modo que el manejo empresarial tiende a la planificación y a la maximización económica.

A pesar de estas diferencias, la tensión entre los modelos tradicional/chacarero en oposición a uno empresarial/no chacarero se observa recurrentemente en $(A)$ y en $(B)$ por igual. Una fuerte valoración por las relaciones familiares en la producción, con más de una generación involucrada - relaciones que tienen su correlato en la propiedad de la tierra, principalmente a partir de las relaciones de herencia - compite con la estrategia de delegar en terceros que no son miembros de la familia. En ambas trayectorias, también se trata de nuevas generaciones que ingresan a la actividad en los últimos años, provenientes de contextos urbanos y atraídos por una mezcla de importantes coyunturas familiares -embarazos, divorcios y enfermedad del productor-, con las nuevas posibilidades de rentabilidad de la producción primaria, a partir de la devaluación de 2002. Por esto, también tienen en común que los jóvenes que se hacen cargo de las decisiones cotidianas de la producción desconocían la actividad. En los dos casos se producen una serie de conflictos que llevan al reemplazo de empleados con mucha autonomía por miembros de la familia. En este sentido, son empresarios que re-familiarizan la gestión de la producción, distanciándose de la tradicional agricultura familiar al incorporar formas de gestión más profesionales.

Por ello, como afirman Pritchard, et al. (2007) para el caso de los productores de tomates australianos, aquí también se trata de empresarios agrarios familiares porque la unidad familiar permanece en el corazón económico y social de la posesión y la operación de las explotaciones, bajo un contexto donde se relacionan con los distintos activos de producción a través de estructuras legales y financieras características de una economía más amplia.

En este sentido, es notable en los casos que la explotación es herencia familiar, las relaciones de parentesco le imprimen una afectividad más ligada a una vinculación tradicional con la propiedad de la tierra, como patrimonio, que como factor productivo.

\section{Como comenta un productor:}

"...la satisfacción más grande mía es, dentro de ese campo [que era] de mi padre, las 150 hectáreas, que es un campo de regular a malo, saco los mejores rindes

\footnotetext{
3 El método CREA se basa en el trabajo grupal de discusión e intercambio de información que realizan los miembros de cada grupo CREA junto a su asesor, quien coordina las tareas de grupo y los asiste técnicamente. Éstos se reúnen una vez al mes para analizar y discutir en profundidad los problemas concretos de una empresa agropecuaria del grupo, y una vez al año para armar el plan de trabajo anual y fijar las metas a alcanzar. Esta metodología permite a los productores conocer, observar y analizar cómo trabajan otras empresas en todos sus aspectos y comparar distintas estrategias productivas y comerciales.
}

de la zona, de campos muy superior a este. Eso es pura y exclusivamente tecnología y rotación..." (Regante 10, Río Segundo, 2008).

Por eso, para estos productores la propiedad de la tierra sigue siendo central, como lo era en el modelo de la agricultura familiar, aunque paralelamente aspiren a convertirse en empresarios agrícolas que trabaja de manera eficiente.

Así, para los regantes "las esperanzas de ir creciendo" es visto como "lo más lindo" de la actividad, que es posible gracias a la innovación que permite "hacer lo mejor posible lo que se estaba haciendo", es decir, con eficiencia, maximizando. Ello constituye "una cuestión de vida, de forma de ser" que permite a este estrato de productores encontrar razones morales para adherir a un capitalismo de avanzada caracterizado por el aumento de la competencia y la concentración de la producción. En este sentido, la "eficiencia" es un atributo fundamental de la práctica agrícola de estos productores, porque en ella obtienen apoyo moral para la realización de su tarea que junto con el progreso material, como advierten Boltanski y Chiapello (2002), son pilares de la justificación de un renovado espíritu capitalista.

\section{Ser Innovador}

\section{El primer regante}

La expresión empresario innovador fue acuñada originalmente por Schumpeter (1963) para describir al actor económico más dinámico del capitalismo. En la definición de Knudsen y Swedberg la innovación es vista como "el acto de creación de una nueva combinación que termina un orden económico y abre el camino para otro nuevo" (2009:16). Involucra al conjunto de la producción económica que, bajo el capitalismo, debe cumplir el requisito de generar ganancia, y es capaz de generar un nuevo orden económico y social como consecuencia de la imitación por parte de competidores que así inician un proceso de difusión que finaliza con el establecimiento de un nuevo orden.

Ser "innovador" es uno de los rasgos constitutivo de la identidad regante. En el caso Pampeano, los productores reconocen mayoritariamente a uno de los regantes como "pionero", ya que fue a partir de su experiencia exitosa que otros decidieron imitarlo incorporando la tecnología. Este productor, un hombre de más de 70 años, descendiente de colonos, heredó de su padre un campo de casi 500 ha. Él es el primer productor de la zona miembro del movimiento CREA, al que se sumó en 1966.

El relato de su experiencia antes y después de incorporar riego está atravesado por el drama de la falta de lluvias, que lo lleva a una situación crítica a causa de las deudas con los bancos y los malos resultados productivos, la 
cual se resuelve decisivamente con la adopción de la tecnología. Luego de una intensa agonía, llega la solución salvadora: la inversión en un sistema de riego más eficiente que se adapte a las condiciones agroecológicas de una zona "floja" para la agricultura, lo que vivió como un momento de ruptura. Su relato es moralizador porque contiene la energía afectiva de las angustias padecidas por la pequeña y mediana producción durante la crisis de la década de 1990, momento en que las deudas que soportaba este estrato de productores comprometían la continuidad de muchos (Lattuada 2000).

Su experiencia se convirtió en un mito fundacional de las virtudes de la tecnología de riego, al mismo tiempo que su comportamiento se erigió como modelo de productor innovador, inspirando con su éxito a otros productores del departamento que decidieron imitarlo.

En este caso, la figura del vendedor de la tecnología tuvo un rol importante, como pieza necesaria, pero no central, ya que había ofertas de diferentes proveedores - a diferencia de lo que sucedió en Traslasierra como se verá más adelante- - La aparición de esta tecnología creó un nuevo mundo de relaciones sociales (Pfaffenberger 1992) - entre los regantes, asesores, vendedores y productores CREA- y representaciones en los que se define lo que "funciona" y es "exitoso" dentro de un medio que facilita el cambio hacia opciones técnicas compatibles con el boom agrícola y la lógica del agronegocio (Cáceres 2013).

Dado que el riego en sí mismo ya era una práctica común para la producción de hortalizas en Córdoba, lo novedoso fue su aplicación bajo un nuevo sistema y para cultivos extensivos en zonas donde la agricultura se realizaba en secano. Si bien este "pionero" no es el creador de la tecnología, ni el primero en adoptarla en Argentina, sí lo es en el caso Pampeano donde despliega un rol particularmente creativo abriendo el camino para que otros productores incursionen en la agricultura extensiva de irrigación. Estos cambios profundos exigen una reinvención creadora por parte de los actores, en tanto son necesarias nuevas prácticas, normas y representaciones sobre la actividad agrícola (Guebel 2000).

La estima que inspira este regante en otros productores se vincula con el rol ejemplificador de pequeño "empresario innovador" que él encarna, lo que se relaciona con la posición que supo ocupar y a la que otros productores pueden aspirar. Como afirma Schiavoni (2008), los casos ejemplares son fundamentales para la construcción de agrupamientos sociales, porque aportan significado a categorías con representaciones no estadísticas "y el buen ejemplo nunca es estadísticamente representativo, de modo que el sentido se elabora asociado a esos miembros centrales en detrimento de los miembros periféricos" (Schiavoni 2008:122).
De este modo, su valor ejemplar se encuentra en que, por un lado, es un productor que cuenta con el prestigio que otorga ser un productor CREA, "una institución de primera", como afirman los productores, pero que no posee grandes extensiones de tierra. Devenido en productor en el marco de la agricultura familiar, es un productor "como uno", es decir, reflejo de la mismidad del resto de los productores del departamento, que pueden compartir con él las condiciones objetivas de producción y reproducción. Por lo tanto, es una figura con la que los productores pueden fácilmente identificarse, que maneja los recursos económicos y cognitivos para distinguirse del productor tradicional a partir de la innovación y lograr el paso de la agricultura de secano a la de riego; una nueva realidad caracterizada por la estabilidad y la previsión que le permitió salir de la crisis en la que se encontraba.

El rol ejemplificador del éxito del "pionero" opera no sólo puntualmente en la adopción del riego, sino también con respecto al comportamiento innovador. Entre los productores regantes existe el esfuerzo consciente por innovar. Esfuerzo que espera ser retribuido no sólo con ganancias económicas, sino con el reconocimiento social de ser "el primero". En este sentido, la autoatribución de varios regantes de ser "los primeros" en incursionar en distintas materias fue una recurrencia significativa en el trabajo de campo. Por ejemplo, entre los regantes entrevistados encontramos productores que declaran ser "los primeros que tenían el equipo de riego funcionando", "el primero y único de la zona que realiza siembra y fertilización variable", "el primero en poner una desactivadora de soja en seco", "el primero en haber realizado feedlot", "los primeros en fertilizar", tener "la primera perforación de riego de la Argentina" y "la primera máquina de siembra directa de la zona", etc.

Sin embargo, la tensión que generan los modelos de agricultura familiar y empresarial condiciona el comportamiento innovador. Ser eficiente, planificar y crecer para sostener una pequeña o mediana producción agropecuaria tiene sentido si sirven para "vivir bien" y estar con la familia. Por eso este es un comportamiento que los regantes explican como el resultado de la necesidad de la economía familiar por aumentar sus ingresos, y el olfato de empresario que señala el cómo hacerlo.

El título de innovador es entonces reclamado por los regantes, el que debe ser manifiesto en el éxito productivo de quien busca ser reconocido. En este sentido, resulta revelador que el intento de ser reconocido como el "primero" aparece, en más de un caso, asociado al orgullo de ser considerado "loco". En este caso, "loco" es quien desafía con su práctica innovadora el statu quo de la producción tradicional. Como si la aventura que implica innovar no fuera lo suficientemente visible en términos sociales, la imputación de una pretendida locura sirve a los productores para destacar el riesgo que enfrenta quién se dispone a ser siempre "el primero". 


\section{Ser un Productor "de Punta"}

\section{Regar es "jugar en primera"}

Los regantes, como actores del capitalismo agrario, orientan su conducta económica hacia la continua acumulación de capital por medios pacíficos. Knudsen y Swedberg (2009) afirman que lo que une esta idea weberiana de capitalismo con la de empresario innovador es el mecanismo de competencia. Si bien la competencia es manifiesta en plano económico, entre los regantes existe también una competencia que no necesariamente se expresa en resultados económicos. Se trata de una dinámica de competencia por la "eficiencia", intrínsecamente vinculada a la identidad de los productores, que se expresa en la presentación de los regantes como "productores de punta".

Así, una de las motivaciones que se destacan en la incorporación de tecnología es la de convertirse en un "productor de punta", porque según los regantes "obviamente, al poner un equipo de riego uno deja, lo que llamamos un lugar de segunda y hay que pasar a primera, entonces hay que jugar con todas las fichas" (Regante "11", Río Segundo, 2008). Esta categoría nativa reafirma su posición en la cúspide de la jerarquía social. En esta lógica, eficiencia e innovación van de la mano, justamente porque la búsqueda de la eficiencia motiva la experimentación.

La posición social que reclaman los regantes cuando se identifican como "productores de punta", no sería posible en base a los volúmenes de producción dada la escala de sus producciones, aunque sí en base a la eficiencia que se expresa en los rendimientos por hectárea y la minimización de los costos, lo que maximizaría las ganancias. La innovación como medio y la eficiencia como fin son criterios elaborados culturalmente por los mismos productores para posicionar a los individuos en una escala de estatus (Velho 2004), más allá de sus atributos económicos. Esta se pone en juego en las interacciones locales, a partir de las relaciones de vecindad que atraviesan la vida cotidiana de los productores como miembros de la comunidad, en las ciudades intermedias del departamento.

Sin embargo, aunque los sistemas de prestigio tienen relativa autonomía, estos no se encuentran disociados de las condiciones materiales (Hatch 1989). Por eso, de esta lógica de competencia ilustrativamente surge lo que los regantes entienden como "rindes del bar". Esta noción hace referencia a la exageración de los resultados de la campaña agrícola, los que no se ven reflejados en el crecimiento económico esperable de quien alardea y que por lo tanto se vuelven sospechosos:

"... vos lo miras a un tipo que es igual que vos, en el campo igual que vos y a él le rinde siempre más que a vos, entonces, vos decís, o sos muy gil para administrarte, o..." (Regante 14, Córdoba, 2008).

La competencia por los rendimientos es incentivada por el riego, donde quien obtiene mayores rendimientos es quien mejor sabe gestionar sus factores productivos y más eficientemente produce. Como afirma uno de los productores,

“... me da gusto regar. Hoy en día, estoy embalado, yo quiero que la soja me dé 60 quintales, quiero que el trigo me dé 70, quiero que el maíz me dé 150, porque sé que el equipo [de riego] me responde..." (Regante 5, Río Segundo, 2008).

Estos criterios de jerarquización centrados en la eficiencia tecnológica son reforzados ante situaciones de rentabilidad del sector menos favorable, y un revés del mercado puede reposicionar a los individuos con un movimiento descendente en la escala social. Así, los productores esperan que cuando la rentabilidad no sea tan buena, "...vas a tener que trabajar mucho más eficientemente" porque "las caídas de precio van a blanquear muchas situaciones" donde se "camuflaba la ineficiencia" (Regante 14, Córdoba, 2008).

En este sentido, cabe destacar que la valoración de la eficiencia en el caso de los regantes del caso Pampeano es hacer de la necesidad virtud, ya que el habitus inclina continuamente a "hacer elecciones ajustadas a la condición de la que es producto" (Bourdieu 1998:174), si consideramos que los aumentos de rendimientos que la testimonian son una exigencia del modelo agrícola vigente dadas las condiciones de mayor competencia que implicó la apertura del mercado y la desaparición de las instituciones de regulación (Azcuy Ameghino y León 2005). Una vez más, la exigencia de eficiencia se hace evidente como parte de la presión que impone la escala. Así, para los regantes perder "eficiencia", es "perder producción, perder rentabilidad, rinde, perder todo..." (Regante 5, Río Segundo, 2008).

De lo hasta aquí analizado se desprende que en el caso de los regantes la competencia por el reconocimiento como un "productor de punta" expresa una lucha por el capital simbólico. La "eficiencia" es el capital en juego, específico del campo, y su reconocimiento, en el contexto local se traduce en mayores ganancias y, por lo tanto, en capital económico. Es en estas relaciones de fuerza simbólica, de competencia, donde se juega la posición social de los productores regantes. Visiblemente ser "de punta" está asociado al uso de la tecnología y, en particular, al riego que da a los productores una marca de distinción concreta. Así, los regantes lograron diferenciarse de aquellos que producen en secano porque esta tecnología los sitúa en otra posición dentro del espacio social (Bourdieu 1990; Bourdieu 1998). 


\section{El caso Traslasierra}

En Traslasierra la agricultura se organiza en torno a la producción de papa para el mercado interno, caracterizada por el uso intensivo de mano de obra y de agua de riego, para el cual se combinan las tecnologías mecanizadas por aspersión con los sistemas de riego gravitacional con agua superficial. Este último data de 1970 y se utiliza casi exclusivamente para la producción de hortalizas, mientras que el riego mecanizado para la producción de granos es un fenómeno de mediados del 2000.

A diferencia del caso Pampeano, en Traslasierra no predomina la agricultura familiar, sino que existen dos formas básicas de organización agrícola: una mayoritaria de tipo campesino, y otras de tipo empresarial-menor en cuanto a la cantidad de personas involucradas pero que abarca grandes extensiones - distinguida por la ausencia de relaciones familiares.

Los productores que utilizan riego mecanizado se ubican entre estos últimos. Ellos poseen EAP's de una extensión media de 1500 ha, aunque entre ellas se encuentran establecimientos de 450 ha como de 4400 ha, la mayor de ellas. El cultivo principal es la papa; seguida de maíz y trigo, aunque las extensiones sembradas con estos cereales son reducidas en relación a la papa. ${ }^{4}$

En Traslasierra hay pocas asociaciones de productores, pero la difusión del riego mecanizado dio lugar a que en 2008 se formara una asociación "tipo CREA" Ilamado "Traslasierra Llanura Norte", replicando la forma de denominación regional de estos grupos. En él se reúnen las 11 empresas agropecuarias de mayor tamaño y nivel tecnológico que se encuentran en Traslasierra, Córdoba, y noreste de San Luis. Estas operan bajo un modelo de agricultura continua integrando el cultivo regional, la papa, con la producción de cereales y utilizando asesoramiento experto permanente.

Así, quienes mayormente utilizan riego mecanizado en Traslasierra son los "grandes productores", aunque no de manera exclusiva. Esta denominación remite a la conformación de un "nosotros" basado en la escala productiva, el tipo de producción -los cultivos extensivosy una "cultura" empresaria que les permite "ver las oportunidades" para hacer negocios. Este último punto es recurrente con lo que sucede con los regantes del caso Pampeano.

El volumen de producción y la distancia a los principales puertos los alienta a industrializar sus productos y

\footnotetext{
${ }^{4}$ Por ejemplo, un productor que cultiva 300 ha de papa, siembra 100 ha de maíz y sólo 50 ha de trigo. Los productores que sólo cuentan con riego gravitacional tienden al monocultivo de papa, y solamente quienes trabajan con tecnología mecanizada producen en mayor medida granos.
}

agregar valor, ya sea al utilizar el maíz como pienso para la producción de leche, desmotar algodón en plantas propias, o industrializar la papa como puré deshidratado, papas bastón o papas chips. ${ }^{5}$ Al mismo tiempo estas EAP's están integradas contractualmente con otras empresas agroalimentarias, como es el caso de la producción de papa con Mc-Cain y de trigo candeal con Molinos Río de la Plata SA.

La agricultura por contrato, con precios sostén para la industria, y la producción de cereales son estrategias que aportan "estabilidad" a las empresas que no dependen de un solo producto destinado al mercado interno y sus vaivenes de precios, como sí lo hacen los productores dedicados exclusivamente al cultivo de papa, los llamados "paperos". Esta diferencia es significativa porque las preferencias por los tipos de productos son indicadores de los distintos perfiles productivos: ". . . los cereales invertís mucho menos plata en la siembra, y si te falla no perdés tanto, pero tampoco nunca vas a ganar mucho. Es una cosa, más estable" (Productor "45". Traslasierra, 2012).

La no diferenciación de los cereales minimiza la competencia entre los productores y facilita su asociación, como se observa en el caso del grupo Traslasierra Llanura Norte que surgió con la introducción del trigo candeal que se cultiva bajo riego mecanizado. El tipo de trabajo grupal que allí se realiza refuerza una cultura empresarial que valora el conocimiento experto y la tecnología. En esta visión lo empresarial está asociado al trabajo metódico de control para una gestión racional y eficiente de la producción, rasgos que comparte con los pequeños y medianos empresarios agropecuarios del caso Pampeano.

La gran diferencia con el caso Pampeano es que los regantes de Traslasierra son empresarios consagrados y por lo tanto no necesitan distinguirse del resto de los productores de la cuenca. Si bien, los "grandes productores" son los regantes por aspersión de Traslasierra, la categoría que los nomina refuerza su identidad a partir de la escala y no de la posesión del riego mecanizado -aunque esté asociada a la tecnología-, siendo además el riego un requisito indispensable para producir en la zona y, por lo tanto, común a todos los agricultores independientemente de su escala.

En este sentido son regantes que no tienen como modelo aspiracional convertirse en algo diferente a lo que ya son y sus estrategias están exclusivamente encaminadas al crecimiento económico y la obtención de ganancias. Aparecen en la escena local a partir de 2005 buscando espacios para realizar su capital, por lo que son ajenos a las tradiciones agrícolas locales y prescinden de las

\footnotetext{
${ }^{5}$ La integración de la actividad productiva para la producción de carne y leche es una estrategia común para que las empresas sean rentables, dado que en Traslasierra la producción de commodities es parte de la rotación con cultivos intensivos y la lejanía de los puertos requiere de destinos alternativos a la exportación.
} 
relaciones de parentesco. Por eso, en Traslasierra la incorporación de riego mecanizado puede entenderse como una estrategia que pone en evidencias los recursos de la gran agricultura capitalista para encontrar nuevos espacios para producir ganancias.

Aunque los "grandes productores" ideológicamente se aproximan a la noción de empresario innovador, estos son actores foráneos, ${ }^{6}$ y el actor local clave para el desarrollo de la agricultura extensiva de irrigación como un nuevo orden agrícola no forma parte de este grupo de productores. De hecho, el principal innovador -en el sentido dado aquí al término- no es un productor agropecuario, sino el propietario de la empresa local proveedora de sistemas de riego mecanizado; un "desarrollador", que como agente de difusión, es responsable en gran medida del nuevo orden social.

Luego de una incursión fallida en la licenciatura de ciencias biológicas, y de un paso desencantador por como guarda parques de Parques Nacionales, en 1985 comenzó a trabajar en la empresa del padre dedicada a la electricidad industrial, especializándose en electrobombas. Después de 10 años de ganar experiencia en ese rubro, en 1995 creó la empresa que actualmente dirige dedicada al desarrollo de los campos con riego, que tiene la representación oficial de la principal empresa de provisión de sistemas de riego en la Argentina, que importa y comercializa equipos Valley:

"...ellos proveen el equipo riego, y nosotros hacemos todo el desarrollo, la parte agrícola, las perforaciones, los estudios de agua, las líneas eléctricas, el desmonte, y después manejo, porque tenemos algunos campos que los manejamos inclusive productivamente también" (Propietario de empresa comercializadora de equipos de riego. Traslasierra, 2012).

Este empresario comenta que cuando empezaron todo era muy nuevo en el país "mucho no se lo conocía", y "costó horrores". Actualmente lleva "desarrolladas" 75.000 ha de riego con pivot central y agua subterránea entre Córdoba, San Luis y Mendoza. De esa superficie, 32.000 ha son las que pertenecen al "Grupo de los 11", coordinado y asesorado por un ingeniero agrónomo asociado a su empresa. En la formación de este grupo, reconoce que tuvo una participación activa, ya que gracias al grupo puede tener acceso a información productiva valiosa que le permite "vender proyectos de inversión sólidos". Lo que considera un valor agregado al hecho de ser el único proveedor de una amplia región con una infraestructura adecuada para brindar servicios posventa

\footnotetext{
${ }^{6}$ La diferencia de origen de las empresas es un dato significativo porque se vincula con su rango de acción y con la constelación de intereses que las motivan (Weber, 2005 [1922]). Son empresarios que tienen equipos de riego en Traslasierra como podrían tenerlos en otras partes del país que presente condiciones de rentabilidad atractivas. Esto supone una diferencia importante con los actores locales que se ve, por ejemplo, en la actitud hacia el cuidado del agua subterránea.
}

de los equipos de riego.

En su caso, las motivaciones para el comportamiento innovador tienen que ver con su percepción de las potencialidades de la moderna agricultura bajo riego con agua subterránea, y las posibilidades de ganancia económica que representan para quien, como él, posea los capitales necesarios. Por ello, él es el principal interesado en velar por la sustentabilidad de los recursos hídricos subterráneos de la cuenca, de modo que se hace cargo de tareas que en realidad corresponden al Consorcio de Usuarios de Agua Subterránea.

Así y todo, los "grandes productores" también son difusores de nuevas tecnología entre quienes intentan imitarlos. Sus estrategias son seguidas inclusive por productores que no están en grupo, como en el caso del cultivo de trigo candeal o algodón, o el uso de nuevas tecnologías como el "poseador". ${ }^{7}$

"...esa tecnología [el poseador] cuando la traen, lo trataban de loco. De hecho lo que pasó el primer año es que hemos roto todas las sembradoras, de sembrar sobre eso, porque uno le pasa al cultivo, perfecto. Después levantás la cosecha, y después tenés que sembrar otro cultivo sobre eso que lo trabajamos con directa. [...] eso es algo muy innovador" (Regante "42". Traslasierra, 2012).

A raíz de ésta última surge un ejemplo claro, al igual que en el caso Pampeano, de cómo lo innovador aparece asociado a "la locura" de quien se atreve a ser "el primero". Porque para ser el primero hay que arriesgar, experimentar con lo desconocido, para obtener beneficios a largo plazo, lo que parece poco razonable en un ambiente conservador. Esta misma apreciación es extensible al sistema de riego por aspersión en su conjunto. Como comenta el encargado de una de las empresas: "yo cuando llegué, esto me parecía chino, que era un programa que no se podía pagar, que era algo que era una locura. Hoy la verdad, digo, pongan riego, cuando se pueda poner, rieguen" (Encargado de Producción. Traslasierra, 2012).

Cabe destacar que la posición de los productores que utilizan riego es clave para entender el proceso de génesis identitaria y los valores asociados a ella. Como vimos en el caso Traslasierra, la creación de categorías de actores como la de "grandes productores" no aparece vinculada del mismo modo al juego de la distinción. Allí los grandes empresarios no compiten con los productores locales, porque la distancia en el espacio social es demasiado grande como para entrar en disputas por el capital simbólico. Esto quiere decir que no necesitan autodefinirse como productores "de punta", y de hecho no lo hacen. Ellos ocupan una posición dominante en el

\footnotetext{
${ }^{7}$ Esta es una máquina para hacer labores de ahuecamiento en la tierra que hace que el agua de riego penetre mejor en el suelo.
} 
espacio local y como tal son poseedores de un prestigio que les es otorgado desde afuera, en mérito de su poder y capacidad económica. Desde el punto de vista de los "grandes productores", el resto de los productores de la zona, como los "paperos", no son productores "como uno", es decir, reflejo su mismidad, ya que no pueden compartir con ellos las condiciones objetivas de producción y reproducción.

Esta característica de no definirse como productores "de punta" repercute en el discurso sobre la eficiencia, que no se encuentra presente del mismo modo que en el caso Pampeano. Así, si bien son empresas integradas por empresarios innovadores, en lo que refiere a la realización de redes de ensayos, nuevos cultivos y uso de nuevas tecnologías, ellos tampoco se preocupan demasiado por aplicar el conocimiento que van obteniendo de estas experiencias. Como evalúan sus propios asesores: "...el productor es capaz de invertir grandes sumas de dinero en un equipo, pero después no lo valora, de decir, [no piensa] 'cómo hago yo para ajustar esto y para que ande a la perfección...'" (Ing. Ag. asesor de riego. Traslasierra, 2012).

Estas evaluaciones son recurrentes, por ejemplo, en la crítica de un asesor sobre el tipo de manejo que hacen los "grandes productores" del sistema de riego mecanizado, una vez incorporado: "automáticamente el paso siguiente, es medir, y no, nadie o muy pocos miden... recién ahora con el grupo se ha empezado a medir, pero miden macroscópicamente" (Técnico, asesor riego. Traslasierra, 2012).

Así el carácter normativo de la eficiencia, en definitiva, es más débil que entre los regantes de Traslasierra que en los regantes del caso Pampeano. Si bien la eficiencia sigue siendo reconocida como un atributo clave para lograr mayor producción y ganancias, pierde su sentido moral y con éste la capacidad para racionalizar la conducta que ella supone, dado que el éxito económico depende de la escala y no de la maximización.

\section{Reflexiones finales}

La adopción del riego mecanizado implica un cambio tecnológico asociado a un nuevo modelo productivo que trajo la agriculturización y la difusión del agronegocio. En los casos estudiados este modelo encuentra en el equipo de riego un símbolo de representación concreto que es además, en el caso Pampeano, parte fundamental de la construcción de una nueva identidad productiva.

Esta identidad es expresada en la categoría "regante", cuyo contenido semántico se articula en torno a la idea de un empresario familiar innovador caracterizado por la eficiencia como valor económico y moral.

Como categoría nativa, el productor "regante" surge en el caso Pampeano donde predomina la agricultura de secano para nombrar un tipo de agricultor particular. Dicha categoría resume el esfuerzo de diferenciarse de lo concebido como el productor "tradicional", el chacarero que hace las cosas como las hizo siempre, sin cálculo ni planificación porque para él la agricultura es una forma de vida, no un negocio.

Y este esfuerzo parte del reconocimiento de que existen, según las representaciones de los productores, dos modelos de producción agrícola. Uno familiar y otro empresarial, que en el caso de los regantes pampeanos, entran en tensión.

Es la tensión entre estos dos modelos de organización lo que caracteriza a los regantes como pequeños empresarios agrícolas familiares, con una fuerte valoración de las relaciones familiares en la actividad dentro de una forma de gestión de tipo "empresarial". Esta es entendida como "eficiente", porque tiende a la maximización; "innovadora", lo que es decir deseosa de incorporar nuevas tecnologías; y "participativa", volcada a la instancias colectivas de asesoramiento experto.

Esta tensión condiciona al comportamiento innovador, un atributo identitario central del regante, ya que lo empresarial -y su rasgo innovador - están en función de lo familiar y su bienestar. Al mismo tiempo, ser reconocido como innovador refuerza el perfil empresario del regante, distanciándolo del productor "tradicional".

Ello hace que esta idea sea traducida a nivel del sentido común como productor "de punta", denominación que es un resultado emergente del mecanismo de la competencia; competencia por la eficiencia que es capital simbólico convertible en capital económico.

Ella es vista como "una cuestión de vida", "una forma de ser" que se basa en cálculo, la medición y la planificación, y que permite alcanzar los objetivos de crecimiento económico. Ella motiva la innovación que es el medio para obtener más ganancias porque se traduce en mayores rendimientos por ha. Pero también es un valor moral, utilizado como criterio de jerarquización social porque testimonia la capacidad maximizadora de un productor que en ese sentido puede ser consagrado como "empresario".

Es por ello que la eficiencia es el capital simbólico que caracteriza a este tipo de productores, gracias a su poder de conversión en capital económico, y define su posición en la "punta" de la pirámide social.

Dentro de esta lógica de distinción y competencia, cabe destacar que si bien puede haber productores "de punta" que no sean regantes, todos los regantes son vistos como productores "de punta", marcando claras diferencias con los otros productores de la cuenca, los que producen en 
secano, justamente porque el riego es el rasgo visible que da cuenta de otro tipo de manejo en otra "realidad" productiva.

Surge entonces una nueva categoría de actores sociales en vinculación con la tecnología, donde ser regante equivale a ser "de punta", lo que desde la perspectiva nativa otorga una posición social destacada, con una serie de atributos económicos, culturales y morales, que condensan las transformaciones del nuevo orden agrícola.

La comparación entre los casos me permitió observar las particularidades propias de cada contexto que ponen de manifiesto cómo se produce la construcción social de la tecnología de riego y valorar su participación en la génesis de nuevas identidades.

Justamente porque el proceso de génesis identitaria que se produce en el caso Pampeano está ausente en Traslasierra, donde los "grandes productores" son empresarios consagrados en virtud de su escala y el riego es un requisito básico y común para la producción agrícola. Ellos son quienes utilizan riego mecanizado con agua subterránea en Traslasierra, pero no se definen como "regantes" ni como productores "de punta", no se comprometen en luchas por el capital simbólico con los productores locales, y por lo tanto, la eficiencia no tiene el peso el moral que tiene en el caso Pampeano. Aunque comparten con los regantes pampeanos rasgos de la cultura empresarial que se impone como modelo en la agricultura del agronegocio.

Buenos Aires, 3 de febrero 2016

\section{Agradecimientos}

Quisiera agradecer a Alejandro J. Gaggero y a los revisores anónimos de la revista por los comentarios y sugerencias que realizaron sobre versiones anteriores de este artículo.

\section{Bibliografía}

Archetti, E. P., \& Stølen, K. A. (1975). Explotación familiar y acumulación de capital en el campo argentino. Buenos Aires: Siglo Veintiuno Editores.

Azcuy Ameghino, E., \& León, C. A. (2005). La «sojización»: contradicciones, intereses y debates. En $X$ Jornadas Interescuelas/Departamentos de Historia. Rosario.

Barros, V. (2008). El cambio climático en la Argentina. En O. T. Solbrig \& J. Adámoli (Eds.), Agro y Ambiente: una agenda compartida para el desarrollo sustentable (pp. 1-35). Buenos Aires: Foro de la Cadena Agroindustrial.

Barsky, O., \& Dávila, M. (2008). La rebelión del campo: Historia del conflicto agrario argentino. Buenos Aires: Editorial Sudamericana.
Barsky, O., \& Gelman, J. (2001). Historia del agro argentino: Desde la conquista hasta fines del siglo XX. Buenos Aires, Argentina: Grijalbo Mondadori.

Barth, F. (1976). Los grupos étnicos y sus fronteras: La organización social de las diferencias culturales. México, D.F: Fondo de Cultura Económica.

Boltanski, L., \& Chiapello, E. (2002). El Nuevo espíritu del capitalismo. Madrid: Akal.

Booth, D. (1994). Rethinking social development: Theory, research, and practice. Harlow: Longman Scientific \& Technical.

Bourdieu, P. (1990). El espacio social y la génesis de las clases. En Sociología y Cultura. México DF: Grijalbo.

Bourdieu, P. (1998). El hábitus y el espacio de los estilos de vida. En La Distinción. Criterios y bases sociales del gusto (pp. 169-174). Barcelona: Taurus, S. A. Grupo Santillana.

Cáceres, D. M. (2013). Tecnología Agropecuaria y Agronegocio. Un Factor Clave para la Expansión del Modelo Agropecuario en Argentina. En VIII Jornadas Interdisciplinarias de Estudios Agrarios y Agroindustriales (pp. 1-22). Buenos Aires: FCE, UBA.

De Janvry, A. (1980). Social differentiation in agriculture and the ideology of neopopulism. En F. Buttel \& H. Newby (Eds.), The rural sociology of the advance societies (pp. 155-168). New Jersey: Allanheld, Osmun \& Co.

Gras, C. (2009). El nuevo empresariado agrario: sobre la construcción y los dilemas de sus organizaciones. En C. Gras \& V. Hernández (Eds.), La Argentina rural. De la agricultura familiar a los agronegocios. (pp. 215-236). Buenos Aires: Biblos.

Gras, C., \& Hernández, V. (2009). El fenómeno sojero en perspectiva: dimensiones productivas, sociales y simbólicas de la globalización agrorrural en la Argentina. En Gras, C. \& V. Hernández (Eds.), La Argentina rural. De la agricultura familiar a los agronegocios (pp. 15-38). Buenos Aires: Biblos.

Guebel, C. F. (2000). Políticas públicas y Cambio Rural. Cuadernos de Antropología Social, 12, 233-251.

Gundermann Kroll, H. (1998). Etnicidad, identidad étnica y ciudadanía en los países andinos y el norte de Chile. Los términos de la discusión y algunas hipótesis e investigación. Estudios Atacameños, 13, 9-26.

Hatch, E. (1989). Theories of Social Honor. American Anthropologist, New Series 91(2): 341-353.

INDEC. (1988). Censo Nacional Agropecuario. (Instituto 
Nacional de Estadística y Censos). Buenos Aires.

INDEC. (2002). Censo Nacional Agropecuario. (Instituto Nacional de Estadística y Censos). Buenos Aires.

Ingold, T. (2000). Tools, minds and machines. An excursion in the philosophy of technology. En The perception of the environment: essays on livelihood, dwelling and skill (pp. 294-311). London: Routledge.

Ingold, T. (2001). Beyond art and technology: The anthropology of skill. En M. B. Schiffer (Ed.), Anthropological perspectives on technology (pp. 17-31). Albuquerque: University of New Mexico Press.

Knudsen, T., \& Swedberg, R. (2009). Capitalist Entrepreneurship: Making Profit through the Unmaking of Economic Orders. Capitalism and Society, 4(2), 1-26.

Lattuada, M. (2000). El crecimiento económico y el desarrollo sustentable en los pequeños y medianos productores agropecuarios argentinos de fines del siglo XX. En Taller de Políticas Públicas, Institucionalidad y Desarrollo Rural en América Latina. Ciudad de México.

Llambí, L. (1988). Small Modern Farmers: Neither peasants nor fully-fledged capitalist? Journal of Peasant Studies, 15(3), 350-372.

Martellotto, E., Salinas, A., Lovera, E., Salas, P., Álvarez, C., Giubergia, J., \& Lingua, S. (2005). Inventario y caracterización del Riego suplementario en la provincia de Córdoba. Boletín INTA, 10, 3-16.

Montenegro, C. (2012). Monitoreo de la Superficie de Bosque Nativo de la República Argentina. Período 2006-2011. Buenos Aires: Dirección de Bosques de la Nación, Secretaría de ambiente y desarrollo sustentable.

Morello, J., Pengue, W., \& Rodríguez, A. F. (2005). Etapas de uso de los recursos y desmantelamiento de la biota del Chaco. En O. Solbrig \& J. Adámoli (Eds.), Agro y Ambiente: una agenda compartida para el desarrollo sustentable (pp. 83-90). Buenos Aires: Foro de la Cadena Agroindustrial.

Murmis, M. (1990). Tipología de pequeños productores campesinos en América Latina. Ruralia, 2, 29-56.

Neiman, M. (2010). La agricultura familiar en la región pampeana argentina. La utilización de los factores de producción y su relación con nuevas dinámicas familiares. Mundo Agrario, 11(21), 1-23.

Peón, C. E. (1992). Sociología rural latinoamericana: Hacendados y campesinos. Buenos Aires: Centro Editor de América Latina.

Pfaffenberger, B. (1988). Objects and Humanised Nature: Towards an Anthropology of Technology. Man, New Series, 23(2), 236252.
Pfaffenberger, B. (1990). The harsh facts of hydraulics: Tecnology and society in Sri Lanka's colonization schemes. Technology and Culture, 21(3), 361-397.

Pfaffenberger, B. (1992). Social Anthropology of Technology. Annual Review of Anthropology, 21, 491-516.

Piñeiro, M.E., \& LLovet, I. (2007). Transición tecnológica y diferenciación social en la agricultura latinoamericana. (Transición tecnológica y diferenciación social en la agricultura latinoamericana.) IICA, San José, Costa Rica.

Pitt-Rivers, J. (1973). El análisis del contexto y el «locus» del modelo. Tres ensayos de antropología estructural. Barcelona: Anagrama.

Pritchard, B., Burch, D., \& Lawrence, G. (2007). Neither 'family' nor 'corporate' farming: Australian tomato growers as farm family entrepreneurs. Journal of Rural Studies, 23(1), 75-87. http://doi. org/http://dx.doi.org/10.1016/j.jrurstud.2006.04.001

Reca, L., \& Parellada, G. (2001). La agricultura argentina a comienzos del milenio: Logros y desafíos. Desarrollo Económico, 40(160), 707-737.

Riera, C. (2015). Agricultura de irrigación en cultivos extensivos: Una estrategia diferente de la producción familiar capitalizada en Córdoba. Realidad Económica, 296.

Riera, C., \& Barrionuevo, N. (2015). La expansión del riego por aspersión en dos áreas agroecológicas de la provincia de Córdoba (1997-2011). Estudios Socioterritoriales, 18, 115-147.

Schiavoni, G. (2008). Nuevas organizaciones agrarias. Plantadores y Campesinos en el nordeste de Misiones. En Campesinos y Agricultores familiares. La cuestión agraria en Misiones a fines del siglo XX. Buenos Aires: CICCUS.

Schumpeter, J. (1963). El proceso de destrucción creadora. En Capitalismo, socialismo y democracia (pp. 118-124). México: Aguilar.

Tort, M. I., \& Román, M. E. (2005). Explotaciones Familiares: Diversidad de conceptos y criterios operativos. En M. C. González (Ed.), Productores familiares pampeanos: Hacia la comprensión de similitudes y diferenciaciones zonales (pp. 35-65). Buenos Aires: Astralib.

Velho, G. (2008). Prestigio y ascenso social: los límites del individualismo en la sociedad brasileña. En A. Grimson, G. L. Ribeiro, \& P. Semán (Eds.), La antropología brasileña contemporánea. Contribuciones para un diálogo latinoamericano (pp. 391-408). Buenos Aires: Prometeo Libros.

Vessuri, H. M. (1980). Technological Change and the Social Organization of Agricultural Production. Current Anthropology, 21(3), 315-327.

Weber, M. (2005 [1922]). Conceptos sociológicos fundamentales. En Economía y Sociedad. México: Fondo de Cultura Económica. 